\title{
Netiquette in Electronic Communication
}

\author{
http://dx.doi.org/10.3991/ijep.v4i3.3570 \\ T. Kozík, J. Slivová \\ Constantine the Philosopher University, Nitra, Slovakia
}

\begin{abstract}
Electronic mail and electronic communications systems are considered significant and effective tools of communication. One of the most widespread electronic communication tools is e-mail communication. In order to avoid misinterpretation of the report on the side of the recipient, it is need to pay attention to the writing of $\mathbf{e}$ - mail messages as well as to their content.
\end{abstract}

With the continuous expansion of the use of electronic communication there have gradually developed certain rules of etiquette in electronic communications. The existing rules of the propriety ones are expressed in the term " etiquette" and are not automatically applied in the new communications environment - media.

For electronic communication, the new rules of etiquette have been stabilised into a term NETIQUETTE. The word netiquette was created by combining words NET (net) and ETIKETA (a set of rules of social behavior and habits). Netiquette constitutes the rules of the behavior of users on a network. Although the netiquette is merely "an unwritten set of rules", their not using can be understood as a type of disrespect.

Analysis of knowledge of domestic and foreign sources as well as results of a survey confirmed the justification of paying attention to the education of individuals in NETIQUETTE, irrespective of the degree of education.

Index Terms-netiquette, electronic communications, net communication, education.

\section{INTRODUCTION}

Regarding the existence of rules of netiquette and their application in communication, we observe interest of users of the electronic network to express an opinion on a number of still opened and unanswered questions, such as the question of the importance and significance of the observance of ethical principles in electronic communications systems.

Another question not yet answered is, why it is appropriate and necessary to pay attention to netiquette in the technical or commercial communication in the electronic communication environment, especially from the perspective of employers. Very interesting is also the question whether NETIQUETTE should be a part of training programs in educational systems. If yes, what should be the content of education, when should we start with it and what forms should be used.

Drawing on the analysis available in domestic and foreign literature and using other supporting sources such as the Internet, education and training objectives of primary and secondary schools and their curricula, contents of information sheets of universities programs, the results of a survey of attitudes of users of electronic communications obtained through questionnaires, we will try to demonstrate the validity, importance and significance of the use of ethical principles in electronic communication systems.

In this paper we focus mainly on determining whether it is necessary to pay attention to NETIQUETTE in technical electronic communications, especially as far as employers are concerned. We will try to answer the question whether NETIQUETTE is part of study programs at higher education institutions and also whether the principles of NETIQUETTE were purposefully created and certified, or they were used only randomly.

\section{NET COMMUNICATION}

In technical articles focused on Netiquette in communication what is mainly stressed is the communication ability of participants. Communication skills in general should have a unique position among other skills of individuals. In communication it is very important to know to express ideas clearly and effectively in written and verbal forms and to avoid ambiguity or misinterpretation of the report by a receiver [1].

Tapscott in his book "Grown Up Digital - How the Net Generation is Changing Your World" mentions the attitude of significant companies as Deloitte and Accenture which understand the impact of the new culture in communication on social changes emerging at the beginning of the 21 st century. These companies believe that Net Gen communication can be crucial in achieving a higher economic performance in the 21 st century [2].

Basic rules of Netiquette were defined nearly 30 years ago [3]. Although Netiquette is considered "an unwritten set of rules", non-compliance to these rules is perceived as a sign of disrespect of communicators.

It is important to note that the ability to communicate is more difficult, if it is done in writing, i.e. in an electronic e-mail form. Therefore, it is necessary to communicate ideas clearly, concisely, and thus avoid their misinterpretation by receivers.

In 1985 Norman Z. Shapiro and Robert H. Anderson defined basic rules of Net communication in their book "Towards an Ethics and Etiquette for Electronic Mail" [3].

According to them, the basic rules of Net communication include:

- Create single subject messages whenever possible

- Assume that any message you send is permanent

- Have in mind a model of your intended audience

- Keep the list of recipients and Cs:s to minimum

- Separate opinion from non-opinion, and clearly label each

- If you must express emotion in a message, clearly label it 
- Think about the level of formality you put in a message

- Identify yourself and your affiliations clearly

- Be selective in broadcast for information

- Do not insult or criticize third parties without giving them a chance to respond.

Similar rules of Netiquette were published by other authors.

Shea V., 1994, Netiquette, extends basic rules of netiquette with the following [4]:

- Remember the human

- Adhere to the same standards of behavior online

- Know where you are in cyberspace

- Respect other people's time and bandwidth

- Make yourself look good online

- Share expert knowledge

- Help keep flame wars under control

- Respect other people's privacy

- Don't abuse your power

- Be forgiving of other people's mistakes.

Kallos J, 2003, Because Netiquette Matters! Kallos is now the E-mail Etiquette expert [5].

- Prompt response,

- Subject field,

- Addressing,

- Prompt response,

- Level of formality,

- To, From, Bcc, Cc and Reply to All fields can make or break you,

- Formatting,

- Attachments,

- Using Previous e-mail for New Correspondence,

- Down Edit Your Replies,

- UCE or Spam,

- Signature files.

\section{NETIQUETTE IN EDUCATION}

At several universities Netiquette is taught through courses. Graduates receive certificates. For example, University in Louisville, Delphi Center, organizes for students seminars on "Netiquette: Get In Write for Professional Email"“[6].

During the courses students learn:

- To avoid unintended harsh tone of expression in the email,

- To write emails that increase, not decrease professional image of writer,

- To send clear and concise reports,

- To send email without clerical errors,

- To write emails faster and better,

- Organisation of email report, i.e. introduction, body, conclusion,

- To control email etiquette and principles,

- To select appropriate style and tone of written expression,
- To format reports for easier reading by the recipient,

- To use attachments, only when it is necessary [6].

In the USA, the University of Kansas, attention of students is focused on the acquisition of skills in technical communication and on the abilities to write and edit information on report correctly. Students are encouraged to enrol into two-week courses of Advanced Technical Communication. Students are led to enrol in a course, which can help them to effectively conclude the Technical Communication Programme without the disturbance to the main study programme.

Courses at the University of Kansas are designed for:

- Students who are expected to write technical documentation in their professional career, especially those who want to work in the area of science, technology and business. A certificate from the area of technical communication which can be stated in their CVs, expands their job opportunities, since most scientists, engineers and entrepreneurs devote significant part of their time to the study, reading or writing technical documentation.

- Students with interest in a career in the technical field, for example in science research, trade and industry. An experienced technical communicator with strong background in this area is desired in the labour market and his/her earnings may be equal or higher than the earnings of many other engineers or scientists.

- A group of professionals who need to increase their technical skills, communication skills, and thereby their added value within the organization in which they work, or those who want to change their jobs, or who have ambition to move vertically or transversely in their current work. Several companies require their employees to steadily increase their soft skills for the company through personal or professional development.

The University of Kansas (KU) offers a complex technical-communication programme aimed at these areas:

- Elements of technical writing - parts that are used to write technical documentation,

- Forms of technical writing - how to design and write various final products, e.g. lab report, specific documents, proposals, user manuals, websites and many more,

- Advanced projects - to create and manage complex projects, documentations.

"Technical communication" is a process of gathering technical information and presenting it to their target group in a clear, useful, accurate, complete, grammatically correct and easy understandable form. The term "technical" includes: scientific, mechanical, chemical, legal, economic, medical, procedural or other specialised information [7].

\section{Netiquette In EdUCATION IN Slovakia}

In order to get relevant information on the teaching of NETIQUETTE at Slovak universities we contacted eight of these institutions. Only two of them confirmed that NETIQUETTE is included in their curricula. The Faculty 
of Informatics and Information Technologies of the STU in Bratislava has a part called "Formal Email" as part of their English lessons, and the MTF STU Bratislava has included NETIQUETTE in the subject called Management Etiquette.

The ČVUT Prague confirmed that they do not have Netiquette in their curriculum, and are not even planning to include it.

With similar intention the authors also contacted IT companies operating in Slovakia. The addressed IT companies have the following common features:

- They represent an international IT company,

- Email communication is a widespread form of communication in society,

- They use professional email communication with customers.

The survey of IT companies was expected to obtain the view of employers regarding the meaning and importance of email communication in the management of their companies. Based on the evaluation of each data items of the questionnaire, aimed at the meaning and importance of non-verbal communication skills of employees, the respondents confirmed the importance of non-verbal communication for their company. The evaluation brought the following conclusions:

- professional and good communication skills of employees increase credibility in contact with customers,

- internet-email is a preferred form of communication in companies,

- internet communication is used in business communication, technical and marketing communication,

- ability of non-verbal communication is very important since it saves time and money and increase credibility of the company,

- low level of non-verbal communication was seen as a result of inefficient preparation at universities.

The conducted survey resulted in the following conclusions:

- Technical engineers have to know how to communicate effectively in written and oral form.

- They have to be able to clearly, objectively and professionally explain the limitations, advantages, disadvantages and benefits for each technical problem.

- Verbal, written, virtual and graphic communication skills of individuals need to be constantly developed and improved at universities.

\section{Merits of EduCATION In NetiQuette}

As far as the application of NETIQUETTE principles in communication is concerned we tried to find the answer to the question of who is interested in accepting NETIQUETTE in electronic communication as well as in its development. Engineers, scientists or workers of other professions?

To answer the question we carried out an analysis of key requirements in the tenders of manufacturing and nonmanufacturing organisations and institutions for jobs in professional technical professions. The analysis showed that soft skills of the candidates are key criterion in selection procedures. Employers consider the main criterion for selecting successful candidates the level of mastering soft skills in communication. According to employers, graduates of engineering study programs have good technical knowledge and skills. Insufficient and critical are, according to them, soft skills, especially communication skills both verbal and nonverbal, i.e. the skills they will need for their jobs. Technical managers are interested in technicians who can articulate their ideas clearly and concisely and express them in written form. In the survey the addressed managers hold an opinion that universities can help students develop these skills if in their curricula they increase emphasis on mastering soft skills of the students, and will encourage students to learn the principles of writing clear and concise technical reports and information. [8].

Technical communication applies to anyone, who creates technical documentation, either engineers, scientists, lawyers or anyone else with special knowledge of certain field as well as professionals who update technical documentation, or editors [9].

From the abovementioned follows that Netiquette does not concern primarily only technicians, but any employee who by email or other electronic form communicates with the customer.

Based on the findings we came to the conclusion that Netiquette should be part of education programs not only at universities, but the principles of NETIQUETTE should be studied at a lower level of education as well. Netiquette should be taught in the form of optional seminar courses. Graduates of these courses would obtain a certificate. For employers, obtaining a certificate would be positive news saying that a job seeker or a new employee is familiar with basics of good communication in work environment. A job seeker who has the certificate increases his/her chance of finding a job and sends a signal to the employer that he/she is willing to continuously improve his/her soft skills.

\section{CONCLUSION}

It turns out that NETIQUETTE in communication is very important and that it is necessary to put more emphasis on its study than before [10].

Although the issue of the application of NETIQUETTE in communication is not a popular research topic, Preece (2004) maintains that there is a diversity of network users in terms of their cultural consciousness, age and ability to express themselves, saying that various communication technologies require different etiquets. For example, etiquette of text messages is different from etiquette of emails. Moreover, there are netiquette variations between web communities as well [4].

Students from all over the world have at their disposal a project called "Global TeachNet News", which aims at supporting and improving the culture of students communication [10].

The analysis of foreign and domestic sources as well as the results of a survey aimed at assessing the significance and importance of using principles of NETIQUETTE in professional and technical communication, not only in technical communication, confirmed the validity of paying attention to the training of individuals in NETIQUETTE irrespective of the level of education. It turned out to be 
PAPER

NeTIQUETTE IN ELECTRONIC COMMUNICATION

particularly important for specialised technical personnel to master soft skills. The soft communication skills of individuals with the capability of applying the principles of NETIQUETTE in communication increase credit of a job seeker interested in finding employment with a prospective employer, or decide on the inclusion of a job seeker to a corresponding working post. Based on the findings, Netiquette should form part of general education and has its place in curricula not only in technical field.

\section{REFERENCES}

[1] THE CITADEL COLLEGE, Technical Writing: For the Engineering Student. [online] available on $<$ http://www.google.sk/url?sa $=$ t\&rct $=\mathrm{j} \& \mathrm{q}=\& \mathrm{esrc}=\mathrm{s} \&$ source $=\mathrm{web}$ $\& \mathrm{~cd}=5 \& \mathrm{cad}=$ rja\&sqi $=2 \&$ ved $=0$ CFQQFjAE\&url $=\mathrm{http} \% 3 \mathrm{~A} \% 2 \mathrm{~F} \%$ 2Ffaculty.citadel.edu\%2Fpotisuk $\% 2$ Felec $104 \% 2$ Fnotes $\% 2$ Fwritte n.ppt\&ei=TWoOUePoGMLTtQazuoHgBQ\&usg=AFQjCNGNKK N7IyDcLJHKmfNc8hW6STlttg\&sig2=5H9DpCHmWPg88x_vk2 QTpQ\&bvm=bv.41867550,d.Yms >

[2] Tapscott, D. 2008. Grown up Digital - how the net generation is changing your world. [online] available on $<$ http://www.grownupdigital.com/downloads/chapter.pdf $>$

[3] Shapiro, N. - Anderson, R. 1985. Towards an Ethics and Ethiquette for Electronic Mail. RAND Corporation. 42 pages. ISBN 978-0833006691

[4] Shea, V. 1994. Netiquette. Albion Books. 150 pages. ISBN 09637025-1-3
[5] Kallos, J. 2004. Because Netiquette Matters!. Xlibris Corporation. pages 188. ISBN $978-1413459814$

[6] The University of Luisville. Get-It-Write Techniques for Professional Emails. [online] available on http://louisville.edu/professionaldevelopment/seminars/communic ation/netiquette

[7] McKitterick, Ch. KU's Technical Communication Liaison. [online] available $<$ http://www.people.ku.edu/ cmckit/TechComm/FAQ.htm>

[8] HISSEY, W.T. 2002. Enhanced Skills for Engineers. [online] available on http://www.todaysengineer.org/2002/aug/skills2.asp

[9] McKitterick, Ch. The University of Kansas. Center for the Study of Science Fiction Director. KU Technical Communication Liaison. [online] available on http://web.ku.edu/ techcomm/

[10] Tedre M.- Kamppuri M.- Kommers P. 2006. An Approach to global Netiquette research. ISBN: 972-8924-10-0

\section{AUTHORS}

Tomáš Kozík is with Constantine the Philosopher University in Nitra, Faculty of Education, Slovakia. He is the Department Chairman of Technology and Information Technologies. ( e-mail: tkozik@ukf.sk )

Jozefína Slivová is a $\mathrm{PhD}$ candidate at Constantine the Philosopher University in Nitra, Faculty of Education, Slovakia. (e-mail: slivova.jozefina@yahoo.com )

Submitted 17 February 2014. Published as re-submitted by the authors 13 June 2014. 